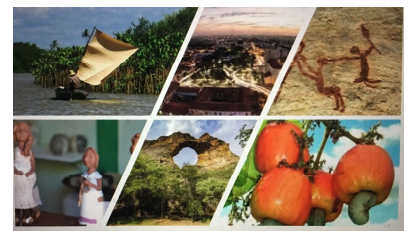

ISBN: 2675-1496 DOI: https://doi.org/10.26694/caedu.v1i2.9895

\title{
ESCOLA, FAMÍLIA E RELIGIÃO CATÓLICA NOS DEBATES EDUCACIONAIS BRASILEIROS (ANOS 1950/60) ${ }^{1}$
}

\author{
Ana Maria Bandeira de Mello Magaldi \\ Professora Associada da Faculdade de Educação \\ Universidade do Estado do Rio de Janeiro
}

\section{RESUMO}

No presente artigo, são analisados os debates educacionais brasileiros conduzidos em torno da primeira Lei de Diretrizes e Bases da Educação Nacional (LDB), sendo conferido destaque às posições da Associação de Educação Católica do Brasil (AEC). No contexto focalizado, situado principalmente nos anos 1950 e até a promulgação da LDB, em dezembro de 1961, ocorreram importantes disputas, tendo como horizonte a definição das políticas educativas, com a expressão de pontos de vista diversos sobre os lugares a serem ocupados por Estado, escola e família na cena educacional. O movimento católico, representado pela AEC e bem próximo, à época, do setor privado da educação, confrontava-se com outro grupo de educadores posicionados em favor da escola pública, obrigatória, gratuita e laica, compreendida como vetor central da democratização da educação brasileira. Apresentando-se em defesa da "família" - identificada à "família católica" - e de seu poder de decisão quanto à escolarização dos filhos, os educadores católicos defendiam a consideração da escolha dos pais pelo Estado e a centralidade das escolas particulares na educação de crianças e jovens, com o apoio de verbas públicas. Tendo como base documental privilegiada o boletim Servir, periódico oficial da AEC, o estudo dialoga com o campo da história cultural e, afinado com Marc Bloch, valoriza a relação indissociável entre passado e presente. Nessa direção, aproxima-se de debates educacionais de nosso tempo, em que o tema das relações entre escola, família e religião ainda tem se expressado com força, assumindo importância crucial para os rumos da educação brasileira.

Palavras-chave: Debates educacionais brasileiros; Movimento católico; Associação de Educação Católica; Relações entre escola e família; Lei de Diretrizes e Bases da Educação Nacional (1961).

\section{SCHOOL, FAMILY AND CATHOLICISM IN THE BRAZILAN EDUCATIONAL DEBATES (1950s/60s)} ABSTRACT

The present article analyzes the Brazilian educational debates held about the Guidelines and Bases for the National Education Law (LDB), with special mention of the views of

\footnotetext{
${ }^{1}$ Este artigo é uma versão atualizada e ampliada da comunicação apresentada no XIII Congreso Iberoamericano de Historia de la Educación Latinoamericana (CIHELA), realizado em 2018, em Montevidéu, com o título: “ 'Em torno da liberdade de ensino': refletindo sobre os debates educacionais brasileiros a partir da Associação de Educação Católica - AEC (anos 1950-1960)”.
}

Revista Caminhos da Educação: diálogos, culturas e diversidades. CAEDU/UFPI

Teresina, Brasil, v. 1, n. 2, p. 141-158, maio/agosto de 2019.

ISBN: 2675-1496 DOI: https://doi.org/10.26694/caedu.v1i2.9895 


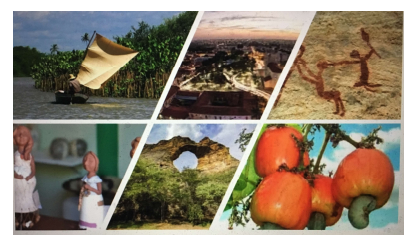

ISBN: 2675-1496 DOI: https://doi.org/10.26694/caedu.v1i2.9895

the Brazilian Catholic Education Association (AEC). Within the targeted context, mainly occurred in the 1950's and until the enactment of the LDB in December 1961, important discussions were undertaken for the purposes of definition of educational policies, with the expression of diverse points of view about the roles to be played by the State, school and family in the educational area. The Catholic movement, represented by the AEC, quite close at the time to that of the private education sector, faced off with another group of educators in favor of public, obligatory, free and secular schools, understood as a central focus of Brazilian educational democratization. Presenting itself as the "family's" guardian - identified as the "Catholic family" - and of its decision-making power regarding schooling of its children, Catholic educators defended consideration of the parent's choice for the State and the centrality of private schooling in the child and adolescent education, with the support of public funding. Using the privileged document, Servir, the official bulletin of the AEC, as a basis, the study debates with the field of cultural history and, in tune with Marc Bloch, values the indissoluble relation of past and present. In this direction, it links to current educational debates, in which the theme of the relations between school, family and religion gain strength, assuming an important and crucial role in Brazilian education.

Keywords: Brazilian educational debates; Catholic movement; Catholic Education Association; school and family relations; National Education Guidelines and Basis Law (1961).

\section{ESCUELA, FAMILIA Y RELIGIÓN CATÓLICA EN LOS DEBATES EDUCACIONALES BRASILEÑOS (AÑOS 1950/60) RESUMEN}

Este artículo analiza los debates educacionales brasileños realizados en torno a la primera Ley de Directrices y Bases de la Educación Nacional (LDB), en los que destacaron las posiciones de la Asociación de Educación Católica de Brasil (AEC). En el contexto enfocado, situado principalmente en los años 1950 y hasta la promulgación de la LDB en diciembre de 1961, se produjeron importantes disputas que tenían como horizonte la definición de políticas educativas, con la expresión de diferentes puntos de vista sobre los lugares a ocupar por el Estado, la escuela y la familia en la escena educacional. El movimiento católico, representado por la AEC y muy cercano en ese momento del sector privado de la educación, se enfrentaba a otro grupo de educadores posicionados a favor de la escuela pública, obligatoria, gratuita y laica, entendida como un vector central de la democratización de la educación brasileña. Al presentarse en defensa de la "familia", a la que se identificaba como la "familia católica", y por su poder de decisión con respecto a la escolarización de sus hijos, los educadores católicos defendían la consideración de la elección de los padres por parte del Estado y la centralidad de las escuelas privadas en la educación de los niños y jóvenes con el apoyo de fondos públicos. Teniendo como base documental privilegiada el boletín Servir, la revista oficial de la AEC, el estudio dialoga con el campo de la historia cultural y, en sintonía con Marc Bloch, valora la relación 


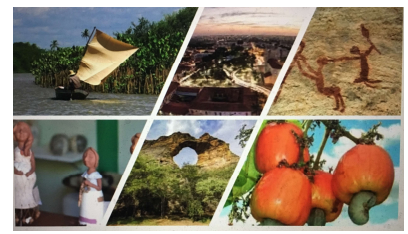

ISBN: 2675-1496 DOI: https://doi.org/10.26694/caedu.v1i2.9895

inseparable entre el pasado y el presente. En esta dirección se acerca a los debates educacionales de nuestro tiempo, en los que el tema de las relaciones entre la escuela, la familia y la religión todavía se expresa con fuerza, asumiendo una importancia crucial en los rumbos de la educación brasileña.

Palabras clave: Debates educacionales brasileños; Movimiento católico; Asociación de Educación Católica; Relaciones entre escuela y familia; Ley de Directrices y Bases de la Educación Nacional (1961).

(...) a escola, considerada até nas suas origens históricas, é por sua natureza instituição subsidiária e complementar da família e da Igreja, e portanto, por lógica necessidade moral deve não somente não contraditar, mas harmonizarse positivamente com os outros dois ambientes, na mais perfeita unidade moral possível, a ponto de poder constituir juntamente com a família e com a Igreja, um único santuário, sacro para a educação cristã, sob pena de falir no seu escopo, e de converter-se, em caso contrário, em obra de destruição. (PIO XI Encíclica Divini Illius Magistri - Sobre a educação cristã da juventude)

\section{O movimento católico e os debates educacionais a partir dos anos 1920}

Em diferentes momentos da história da educação brasileira, desenvolveram-se - e continuam em curso - debates relevantes, evidenciando disputas e projetos no campo educacional, tendo como horizonte a interferência nas políticas públicas relativas ao tema. No trecho reproduzido acima, da encíclica lançada pelo Papa Pio XI em 1929, são encaminhadas orientações sobre o lugar da escola, da família e da Igreja na educação das novas gerações, que representaram uma referência crucial para as posições católicas expressas no campo educacional brasileiro.

Nos anos 1920, quando o documento papal veio a público, ações diversas já vinham sendo conduzidas, congregando intelectuais e educadores católicos que, capitaneados pela hierarquia da instituição, constituíram um amplo movimento tendo como eixo de luta a retomada do espaço perdido pela Igreja Católica na sociedade e na educação brasileira, a partir da afirmação do regime republicano. Com a República, havia sido instituída a separação entre Estado e Igreja Católica no país e a laicidade da educação pública, situação que marcava uma ruptura significativa com um longo passado educacional, caracterizado pela presença central do catolicismo, estimulando a 


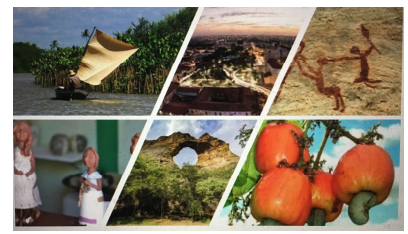

ISBN: 2675-1496 DOI: https://doi.org/10.26694/caedu.v1i2.9895

organização de setores católicos empenhados no retorno do ensino religioso às escolas públicas brasileiras.

Após a chegada de Getúlio Vargas ao poder em 1930, a que se seguiu um quadro de indefinição quanto aos rumos da política educacional, acirraram-se as tensões entre esses setores católicos e o grupo de educadores vinculados ao movimento da Escola Nova, que também assumia expressão crescente na época. Os "escolanovistas" posicionavamse fortemente, então, em defesa de uma escola pública laica, além de obrigatória, gratuita e comum a todas as crianças e jovens, ponto de vista que aproximava educadores que compuseram um movimento de viés bastante plural. Essa tomada de posição coletiva tornou-se pública no Manifesto dos Pioneiros da Educação Nova de 1932, marcando uma distinção do grupo em relação ao projeto católico.

Já os educadores inscritos no movimento católico, enfatizavam a crença na impossibilidade de promoção de uma educação integral e de qualidade sem a dimensão religiosa, defendendo, por isso, sua presença no currículo das escolas públicas. Compreendiam, ainda, que essa seria uma forma de as famílias católicas serem contempladas na educação de seus filhos, que seria conduzida em sintonia com seus valores.

Nesse enfrentamento, o movimento católico obteve uma importante vitória, com a edição, por Vargas, de um decreto reintroduzindo o ensino religioso nas escolas públicas, em abril de 1931. Através desse instrumento legal, o governo varguista dava um importante passo na direção do estabelecimento de uma aliança com a Igreja Católica, com a aproximação entre a política educacional adotada e as orientações apresentadas pela Encíclica Divini Illius Magistri (Sobre a educação cristã da juventude).

Em um contexto de redefinição dos rumos políticos do país, após o fim do Estado Novo, a Constituição de 1946 previu a regulamentação do tema educacional através de uma lei própria, que deveria ser alvo de debates e deliberação do Congresso Nacional. Ao longo de treze anos, puderam ser observadas disputas acirradas em torno dessa lei, que terminou sendo editada em dezembro de 1961 como a primeira Lei de Diretrizes e Bases da Educação Nacional e, entre os setores de maior destaque nesse embate, situaram-se, Revista Caminhos da Educação: diálogos, culturas e diversidades. CAEDU/UFPI 


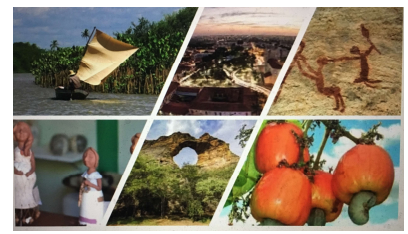

ISBN: 2675-1496 DOI: https://doi.org/10.26694/caedu.v1i2.9895

de um lado, o grupo católico recomposto e, de outro, os remanescentes do movimento "escolanovista" a que se somaram outros educadores e intelectuais da nova geração.

Nesse cenário, os debates em torno das relações entre escola, família e religião foram atualizados e o movimento católico, reagrupado, retomou a Encíclica de Pio XI como fonte de inspiração, reforçando a ideia da educação cristã da juventude e da preeminência da família na educação de crianças e jovens. Em 1945, esse movimento passou a contar com uma nova entidade voltada para a representação dos setores educacionais: a Associação de Educação Católica do Brasil (AEC). ${ }^{2}$ Sobre a fundação dessa associação, um aspecto merece registro, por sua particularidade e pelo significado de que se revestiria no quadro das lutas educacionais do período. Trata-se do fato de a entidade ter sido gestada a partir do I Congresso Nacional de Diretores dos Estabelecimentos Particulares de Ensino, realizado em 1944. Essa aproximação entre o segmento católico e o setor privado do ensino, já na fundação da AEC, se tornaria mais estreita ao longo dos debates sobre a Lei de Diretrizes e Bases (LDB).

No processo de afirmação dessa associação, passou a circular, em 1947, como publicação oficial, o boletim Servir, reunindo em suas páginas informes sobre as atividades da AEC, notícias do movimento católico no exterior e comentários sobre as questões em debate à época, incluindo poucos artigos assinados. Era comum, também, o boletim trazer palavras do Papa, reforçando a relação direta da associação com a hierarquia da Igreja. Elegendo o professorado católico como um alvo destacado, a quem também procurava dar voz, a publicação representava uma estratégia valiosa para o movimento, na direção da produção de consensos e do fortalecimento das posições da Igreja Católica e da associação que atuava em seu nome, no cenário educacional de então. ${ }^{3}$

\section{A reorientação dos posicionamentos católicos nos debates da LDB}

\footnotetext{
${ }^{2}$ No momento anterior, uma outra entidade havia assumido importância nos debates e na representação católica: a Confederação Católica Brasileira de Educação (1933-1938).

${ }^{3}$ Sobre o conceito de estratégia, cf. CERTEAU, 1994 e sobre a imprensa educacional, cf., entre outros estudos, NÓVOA, 1997.
}

Revista Caminhos da Educação: diálogos, culturas e diversidades. CAEDU/UFPI 


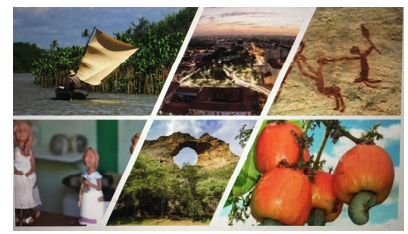

ISBN: 2675-1496 DOI: https://doi.org/10.26694/caedu.v1i2.9895

A partir da análise dos textos desse periódico, é possível perceber que os posicionamentos católicos quanto ao tema educacional ainda se apoiavam, nos anos 1950, na própria Encíclica Divini Illius Magistri, de 1929, e o grupo atuante no novo contexto parecia empenhado no atendimento às orientações presentes no documento, mirando o aprofundamento das ações nessa direção e o fortalecimento da presença do catolicismo na educação das novas gerações. Segundo Pio XI, as escolas "abertas indiferentemente para católicos e não católicos, sem distinção" e nas quais era dada "em separado a instrução religiosa", sendo o restante do ensino recebido "em comum com os alunos não católicos de professores acatólicos", somente poderiam ser toleradas em situações excepcionais. De acordo com a visão apresentada, as instituições organizadas desse modo não corresponderiam "aos direitos da Igreja e da família cristã (...), sendo comum a instrução religiosa fosse conduzida "com bastante parcimônia.” (PIO XI, 1929, p.20)

Ainda que a reintrodução da religião nas escolas públicas tivesse representado a conquista mais relevante do movimento católico no campo educacional na década de 1930, consolidando uma orientação que se mantinha vigente nos anos 1950, neste novo cenário, vozes diversas assinalavam que aquela medida, da forma como havia sido instaurada, envolvendo uma única aula de religião dissociada do restante da formação dos alunos, teria conduzido a resultados limitados e insatisfatórios. Diante desse diagnóstico, foi-se conformando a visão de que a estratégia adotada para a consolidação das relações entre educação estatal e religião deveria ser revista.

O documento papal indicava que, para uma formação católica sólida, seria:

(...) indispensável que todo o ensino e toda a organização da escola: mestres, programas, livros, em todas as disciplinas, sejam regidos pelo espírito cristão, sob a direção e vigilância maternal da Igreja católica, de modo que a Religião seja verdadeiramente fundamento e coroa de toda a instrução (...). É mister, para nos servirmos das palavras de Leão XIII, que não só em determinadas horas se ensine aos jovens a religião, mas que toda a restante formação respire a fragrância da piedade cristã. (PIO XI, 1929, p.21)

Essa diretriz era seguida pelas escolas confessionais católicas, que traziam, como um aspecto central de seu projeto educacional, a adesão aos desígnios da Igreja e a correspondência às expectativas das famílias católicas. Na década de 1950, o setor 


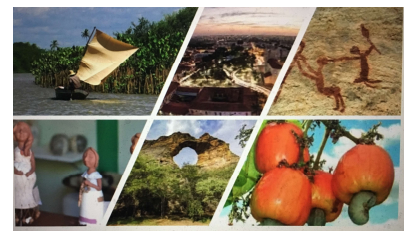

ISBN: 2675-1496 DOI: https://doi.org/10.26694/caedu.v1i2.9895

privado do ensino já ocupava um lugar expressivo na cena educacional brasileira e o segmento católico, composto por escolas vinculadas a congregações e ordens religiosas, detinha a hegemonia nesse conjunto, principalmente no nível secundário. O que era detectado como um problema, pelos educadores católicos, na concretização do projeto de construção da "nação católica" então atualizado, ${ }^{4}$ era o fato de grande parte das famílias católicas brasileiras não possuir condições financeiras de arcar com os custos necessários para ter seus filhos estudando nessas instituições. De acordo com o grupo envolvido nas discussões em torno da LDB, seria fundamental que o Estado garantisse condições para que essas famílias tivessem a sua "liberdade de consciência" assegurada, e para que os alunos oriundos das mesmas frequentassem instituições escolares cujo projeto formativo estivesse sintonizado com sua fé.

Na mesma encíclica de 1929, Pio XI tratava do tema, apoiando-se, inclusive, em soluções dadas ao problema, em países diversos:

\begin{abstract}
Nem se diga ser impossível ao Estado, numa nação dividida em várias crenças, prover a instrução pública por outro modo que não seja a escola neutra ou a escola mista, devendo o Estado mais razoavelmente, e podendo também mais facilmente, prover, deixando livre e favorecendo até com subsídios a iniciativa e obra da Igreja e das famílias. E que isto seja realizável com satisfação das famílias, com utilidade da instrução, da paz e da tranquilidade pública, bem o demonstra o facto de haver nações divididas em várias confissões religiosas, onde a organização escolástica corresponde ao direito educativo das famílias, não só quanto ao ensino, particularmente com a escola inteiramente católica, para os católicos, mas também quanto à justiça distributiva, com o subsídio financeiro da parte do Estado, a cada uma das escolas desejadas pelas famílias. (PIO XI, 1929, p.21)
\end{abstract}

Nesse trecho do documento, aparece a crítica à escola pública laica - ou neutra -, tal como continuavam a defender os "escolanovistas", mesmo após a derrota sofrida com o decreto de 1931, e também àquele modelo de escola estatal instituído por esse instrumento legal, em que se observaria a formação religiosa - vista como insuficiente para a obtenção dos resultados desejados - de alunos cujas famílias assim o desejassem. Em outra direção, mirando a educação cristã nas bases consideradas apropriadas, a

\footnotetext{
${ }^{4}$ Segundo estudo de Sergio Montalvão, "Enquanto na Primeira República viveu-se um momento de recuperar o Brasil para a grande nação católica, no final dos anos 1950, queria-se evitar que a nação católica se perdesse frente às imposições do mundo moderno." MONTALVÃO, 2010, p. 10.
}

Revista Caminhos da Educação: diálogos, culturas e diversidades. CAEDU/UFPI

Teresina, Brasil, v. 1, n. 2, p. 141-158, maio/agosto de 2019.

ISBN: 2675-1496 DOI: https://doi.org/10.26694/caedu.v1i2.9895 


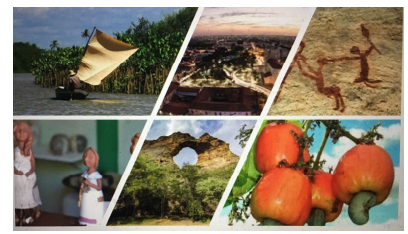

ISBN: 2675-1496 DOI: https://doi.org/10.26694/caedu.v1i2.9895

encíclica apresentava um argumento que seria muito utilizado pelo movimento católico no novo contexto, em sua luta pelo apoio do Estado às escolas confessionais: o da subvenção financeira.

Esse tema, inscrito na discussão relativa ao papel da esfera pública e privada na educação, foi um dos mais relevantes nos debates sobre a LDB e foi um daqueles que mais fortemente atraíram a oposição dos setores que permaneceram na luta em favor da democratização da educação brasileira tendo como vetor central a escola pública. As posições desse grupo, reunindo a antiga geração de "escolanovistas" a que se agregaram educadores e intelectuais atuantes nesse outro momento, identificados na defesa da escola pública, obrigatória, gratuita e laica, foram publicizadas, em julho de 1959, por intermédio de um Manifesto, que apresentou em seu título a expressão "Mais uma vez convocados". A expressão escolhida marcava sua nítida vinculação com o movimento educacional dos anos 1930 e com o documento emblemático de 1932, indicando a retomada de pontos de vista e o reforço de bandeiras levantadas naquele momento anterior, ações que também passariam a ser conduzidas pela Campanha em Defesa da Escola Pública, organizada nesse mesmo quadro das lutas em torno da LDB.

No que se refere aos setores católicos, pôde ser observado, no cenário dos anos 1950, o estreitamento de sua aproximação em relação ao segmento dos proprietários de colégios particulares, sendo que ambos os lados, ainda que sem fundamentação consistente, acusavam os educadores comprometidos com a educação democrática e com a escola pública de pretender estabelecer o "monopólio estatal da educação", ameaçando, assim, a liberdade de atuação das escolas particulares. Indo além das ideias de "liberdade de ensino", ou do "ensino livre", expressões por meio das quais tentavam traduzir a sua pauta de combate a uma situação denunciada, em que a escola estatal teria exclusividade na educação das novas gerações, os educadores católicos produziam toda uma argumentação dirigida à defesa do apoio financeiro do Estado para as escolas privadas confessionais.

Entre os aspectos demandados por esses grupos, apresentava-se a subvenção do Estado voltada para o pagamento de salários condignos aos professores, auxílio Revista Caminhos da Educação: diálogos, culturas e diversidades. CAEDU/UFPI 


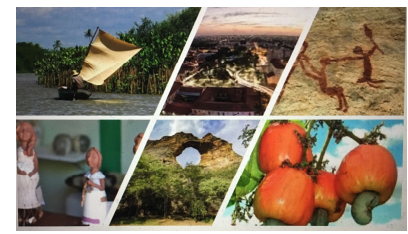

ISBN: 2675-1496 DOI: https://doi.org/10.26694/caedu.v1i2.9895

justificado com base no fato de que a legislação vigente limitava os percentuais de reajuste das mensalidades escolares, restringindo, consequentemente, os recursos financeiros das instituições de ensino. Esse tema foi focalizado nas páginas do boletim Servir, como no artigo intitulado "Remuneração dos professores particulares", de março de 1952, que reproduzia e elogiava uma matéria publicada anteriormente em O Estado de São Paulo. O texto dava notícia sobre um anteprojeto formulado por entidades ligadas ao ensino particular e enviado à Comissão de Educação e Cultura da Câmara dos Deputados, que adotava um enfoque na mesma direção daquele assumido pela AEC.

Segundo o que era apresentado no artigo, publicado originalmente em um jornal diário de grande circulação, a liberdade de ensino, no caso das famílias desprovidas de recursos financeiros para sustentar o pagamento de mensalidades, somente se efetivaria com o auxílio das verbas públicas. A defesa da família e a representação da Igreja e dos educadores católicos como seus porta-vozes, assim como ocorreu no cenário das décadas de 1920/1930, aparecia com força novamente nesse outro momento.

Mais uma vez tornando visível a presença do debate educacional na grande imprensa, em dezembro de 1959, o Boletim Servir transcrevia um artigo opinativo do jornal $O$ Globo intitulado "Nem comercialização, nem politização da escola". O texto defendia o projeto de Lei de Diretrizes e Bases em debate na Câmara Federal, também apoiado pelo grupo católico, ${ }^{5}$ contrapondo-se aos críticos do mesmo, que identificariam no conteúdo da lei a condenação da escola pública ao "extermínio". De acordo com o artigo, "Cada família, cada grupo social tem direito a formar-se numa filosofia de vida que, por definição democrática, não cabe ao Estado ditar.” (Servir, dez./1959, p. 13).

\footnotetext{
${ }^{5} \mathrm{O}$ projeto em debate nesse momento assumia a feição do substitutivo apresentado pelo deputado Carlos Lacerda (UDN/DF) à Comissão de Educação e Cultura, em novembro de 1958, representando os interesses dos setores católicos ligados às escolas confessionais e dos empresários da educação. Enfatizando a ideia de "liberdade de ensino", "procurou fixar em lei os dispositivos capazes de assegurar os direitos da família e dos particulares em receber e ofertar os préstimos educativos". (MONTALVÃO, 2010, p. 9)
} 


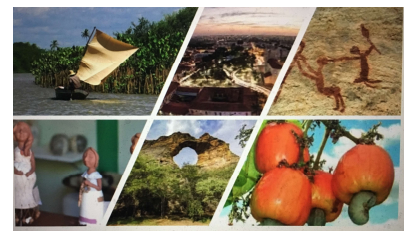

ISBN: 2675-1496 DOI: https://doi.org/10.26694/caedu.v1i2.9895

Criticando a ideia de uma escola estatal que impusesse a todos um ensino neutro em matéria religiosa - ainda que, no caso brasileiro, o ensino religioso estivesse previsto pela legislação, desde 1931 -, o texto posicionava-se a favor do apoio do Estado para as escolas privadas, possibilitando às famílias pobres católicas a escolha de um tipo de formação a ser dada aos filhos, nas bases preconizadas pela Igreja. Essa alternativa apresentava-se em confronto com a ideia da escola pública como única gratuita, que as famílias, "contra sua consciência" poderiam vir a se sentir constrangidas a aceitar, o que era indicado como "prepotência do Estado", traduzida na seguinte afirmação: "Se a escola estatal é a única gratuita, não há escolha para o pobre.” (Servir, dez./1959, p. 14)

Expressando uma interpretação particular do tratamento dado pela Constituição de 1946 ao tema da educação pública, o texto sublinhava: "O que se deve dizer ao povo é que a Constituição the garante escolher a escola e que o Estado se obriga a supri-lo dos meios necessários a cursá-la, já que para isso ele lhe cobra pesados impostos." Ainda como reforço da argumentação desenvolvida, o artigo fazia referência elogiosa a uma solução dada ao tema da educação na Bélgica, envolvendo a "igualdade de condições para as escolas oficiais e livres” (p. 12) e a subvenção de escolas privadas pelo poder público:

\begin{abstract}
A escola pública, como a entendem a Bélgica e as nações verdadeiramente democráticas, é a que "se abre ao público, respeitando a vontade da família na escolha." (...) Nem comercialização nem politização da escola. O que se impõe é o resguardo dos direitos da pessoa humana, o reconhecimento de que a estandardização dirigida não pode, sem grave dano, aplicar-se ao ensino. Facilite-se a todos o acesso às fontes da educação. Mas, suprimir dela a escolha é matar a democracia no seu nascedouro - a eterna obsessão da tirania totalitária. (Servir, dez./1959, p. 14) ${ }^{6}$
\end{abstract}

O compartilhamento de um texto que trazia a crítica à mercantilização do ensino sugere uma tentativa de distinção do grupo católico em relação aos setores empresariais da educação. Se essa foi a abordagem observada nesse artigo, o que parece ter prevalecido, na maior parte do tempo, em meio aos posicionamentos dos educadores

\footnotetext{
${ }^{6}$ A referência à "tirania totalitária" pode ser compreendida no contexto do debate em curso, em que também eram observadas críticas dirigidas ao excesso de centralização do sistema educacional oriundo do período ditatorial do Estado Novo.
}

Revista Caminhos da Educação: diálogos, culturas e diversidades. CAEDU/UFPI 


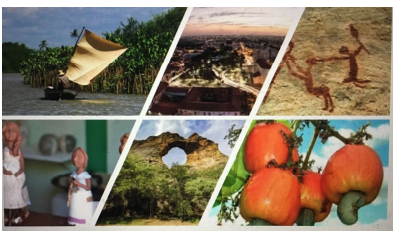

ISBN: 2675-1496 DOI: https://doi.org/10.26694/caedu.v1i2.9895

católicos, foi o silenciamento sobre sua aproximação do segmento composto por proprietários de colégios não confessionais (SENRA, 2010, p. 75 e 76), o que indica que a relação com este setor não teria sido assumida claramente enquanto tal. Apesar disso, a análise dos pontos de vista apresentados por esses grupos no quadro dos debates em torno da LDB pode nos levar a compreender que tenha se estabelecido uma aliança, estreitada ao longo desse processo.

Em um outro artigo da publicação da Associação de Educação Católica, assinado por C. Junqueira e escrito em resposta a um texto publicado anteriormente por Jaime de Abreu, educador marcado pela aproximação da tradição escolanovista e pela defesa da escola pública, o projeto de Lei de Diretrizes e Bases em tramitação era defendido:

\begin{abstract}
A nova lei de educação, além de pôr em prática a descentralização administrativa, defende também a tese da descentralização pedagógica. Nesse sentido, ela garante a liberdade de ensino aos diferentes grupos associados de modo a obter aquela pluralidade pedagógica que caracteriza os regimes educativos democráticos e os distingue dos totalitarismos uniformizadores. Com o mesmo intuito, ela assegura a todas as famílias o exercício do direito que lhes outorgam a Constituição brasileira de 1946, o Código Civil Brasileiro e a Declaração Universal dos Direitos do Homem, ${ }^{7}$ artigo 26, que diz: "os pais têm, como prioridade, o direito de escolher o gênero de educação a ser dada aos seus filhos". (JUNQUEIRA, ago./1960, p. 16)
\end{abstract}

Se um dos principais argumentos mobilizados para o estabelecimento de subvenções às escolas confessionais envolvia a precariedade das condições financeiras de muitas famílias católicas brasileiras, a defesa desse tipo de medida não se limitava a esses casos. Indicando uma compreensão mais ampliada do que era considerado um direito, os educadores católicos vinculados a congregações e ordens dedicadas à educação, aliados aos proprietários de escolas privadas, mobilizavam com muita intensidade a noção de justiça distributiva para embasar seus pontos de vista, apresentados de forma recorrente na publicação da AEC. No artigo citado, era questionada a ideia de "defesa da Escola Pública", em nome da qual Jaime de Abreu se manifestava, assim como era problematizada a perspectiva adotada por este educador, de crítica à ameaça que estaria

\footnotetext{
${ }^{7}$ O autor demonstra realizar uma leitura particular da Constituição de 1946 e da Declaração Universal dos Direitos Humanos, reforçando a subordinação da escola à fam.
}

Revista Caminhos da Educação: diálogos, culturas e diversidades. CAEDU/UFPI 


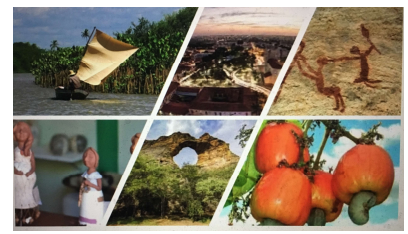

ISBN: 2675-1496 DOI: https://doi.org/10.26694/caedu.v1i2.9895

sendo representada pela lei, em vias de ser editada. Segundo o texto, a referida ameaça à escola pública não existiria, "já que a Escola Pública é a que o povo deseja e não a que o Estado impõe (...).” (Ibidem, p. 17)

Em matéria publicada na mesma edição do boletim, intitulada "Palavras do episcopado francês sobre a questão escolar", é reproduzida reflexão do Bispo Paul Gouyon, de Bayonne, evidenciando aproximações entre setores católicos brasileiros e franceses, sobre o tema mencionado:

Os fundos públicos não são outra coisa senão os fundos particulares postos à disposição do Estado por todos os cidadãos. (...) Particulares pela sua origem, tornam a sê-lo frequentemente pelo seu destino, sem que ninguém pense, sequer, em se escandalizar. (...) Por que não teriam nossas escolas o direito de se beneficiarem destes fundos? (Servir, ago./1960, p. 21)

Apoiada na mobilização de argumentos como os que aparecem nessas citações, a referida aliança privatista entre setores católicos e empresariais teve demandas contempladas na Lei de Diretrizes e Bases da Educação Nacional editada em dezembro de 1961, o que pôde ser observado na questão do direcionamento de verbas públicas para instituições particulares de ensino. Já em agosto deste ano, a aprovação do projeto em questão na Câmara dos Deputados era saudada por C. Junqueira, no artigo citado, em que demonstrava confiança em sua aprovação também no Senado, o que terminou acontecendo poucos meses depois. Na visão do autor, essa Lei de Educação abriria

(...)para o país as perspectivas da verdadeira educação democrática, universal e gratuita, respeitada a prioridade da família, na escolha da escola para seus filhos e seus direitos na participação, através de bolsas para os alunos pobres, dos recursos do orçamento, já que o Estado não é proprietário dos dinheiros públicos, mas mero administrador, e fiel à filosofia democrática, deve estabelecer processos de justiça distributiva, sem nenhuma forma de discriminação que cerceie a liberdade de consciência." (JUNQUEIRA, ago./1960, p. 17)

Através da análise dos artigos do Boletim Servir, é possível perceber que noções de "democracia", "liberdade" e "público" foram ressignificadas pelo grupo católico, em meio aos debates então conduzidos, assumindo sentidos bem diversos daqueles presentes nas formulações e nas lutas encaminhadas pelos educadores vinculados à defesa da escola 


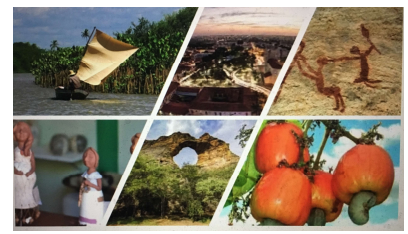

ISBN: 2675-1496 DOI: https://doi.org/10.26694/caedu.v1i2.9895

estatal e laica. Para a reflexão sobre essa disputa de sentidos no passado - e também no presente -, torna-se interessante dialogar com os estudos de Roger Chartier e com a perspectiva de "lutas de representação"

\section{Família e escola nos debates educacionais do passado e do presente}

O contexto democrático em que se deu a tramitação da LDB - conduzida, na maior parte do tempo, durante o governo de Juscelino Kubitschek e encerrada no governo de João Goulart - sofreria uma dura interrupção, pouco tempo depois da edição da lei, com o golpe civil-militar de 1964. A ditadura e a repressão política que se instalaram em seguida impediram a continuidade dos debates educacionais, assim como a participação da sociedade nos rumos do país. Após duas décadas de regime militar, o processo de redemocratização do país, situado a partir da década de 1980, trouxe em seu bojo a retomada de discussões sobre políticas educacionais, quando as disputas em torno da alocação de verbas públicas na educação voltaram à cena. Essa questão mantém-se, até nossos dias, como um tema central, envolvendo enfrentamentos entre grupos posicionados em defesa do direcionamento das verbas públicas para a educação pública e setores partidários de políticas que priorizam o apoio financeiro do Estado à educação privada, contribuindo, inclusive, para o esvaziamento das instituições públicas de ensino.

Uma outra questão em que se percebem fortes aproximações entre passado e presente envolve as concepções sobre o papel das instituições e sujeitos educativos na formação de crianças e jovens. Nos contextos focalizados, a Igreja Católica e os agentes que atuavam sob sua liderança conferiram grande destaque à família, apresentada como núcleo central da sociedade, identificada a um sentido de unidade e abordada, sem nenhuma distinção, como "família católica". Valorizando a preeminência da instituição familiar diante da escola e posicionando-se em favor da garantia de sua liberdade e da transmissão de seus princípios no espaço escolar, o movimento católico compreendeu, no cenário dos anos 1950, que tal horizonte somente seria atingido nas escolas confessionais, que, por sua vez, deveriam contar com o apoio do Estado e de verbas públicas. 


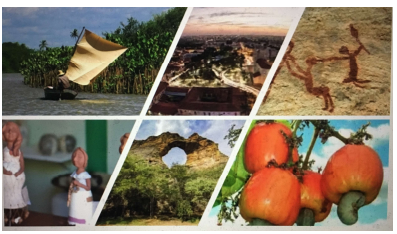

ISBN: 2675-1496 DOI: https://doi.org/10.26694/caedu.v1i2.9895

Indo além do tema especificamente educacional, mas fortemente articulado ao mesmo, observa-se, nesse quadro, que setores católicos também se mobilizaram em torno de um projeto mais amplo de sociedade, que encontraria em valores como tradição, autoridade e hierarquia referências importantes para sua constituição. Tais valores, enfatizados também no âmbito do que era concebido como a vida familiar e a educação escolar católica, embasariam os posicionamentos daqueles grupos, aproximando-os de outros setores envolvidos na conspiração contra o governo João Goulart, em um cenário em que marcas conservadoras e autoritárias, progressivamente, se mostrariam visíveis. ${ }^{8}$ Essa representação de sociedade seria encenada, mais tarde, em 1964, nas chamadas Marchas da Família com Deus Pela Liberdade, inscritas na movimentação em torno do golpe civil-militar, quando se afirmou a vitória do projeto em questão. Nessas manifestações, pôde ser percebida a forte presença de católicos e, em particular, de mulheres católicas, muitas das quais envolvidas na própria organização e liderança das mesmas, com o apoio da hierarquia da Igreja. ${ }^{9}$

Essa concepção de sociedade mostrava-se muito distanciada de outras perspectivas, compartilhadas por educadores daquele tempo, que valorizavam a centralidade da escola pública e do direito universal à educação como um importante caminho para a democratização da própria sociedade, e compreendiam a noção de liberdade a partir das práticas escolares, em seu exercício cotidiano por professores e alunos. Tendo essa tendência sido barrada e pela ditadura militar, com a repressão a projetos educacionais democratizantes desenvolvidos nos anos 1960 e a educadores

\footnotetext{
${ }^{8} \mathrm{O}$ anticomunismo se constituiu, neste contexto, em um ideário compartilhado por movimentos e grupos diversos implicados na desestabilização do governo João Goulart, sendo observável também no caso de setores católicos. Cf. MOTTA, 2002.

${ }^{9}$ No Rio de Janeiro, foi fundada a Campanha da Mulher pela Democracia (CAMDE), em 1962, associação feminina vinculada à Igreja Católica, que esteve envolvida na conspiração contra o governo João Goulart e na organização da "Marcha da Vitória", no dia 2 de abril de 1964. Em outras cidades brasileiras, foram fundadas associações semelhantes, na mesma época, também envolvidas na mobilização política que conduziu à deposição do Presidente Goulart, como foi o caso da União Cívica Feminina (UCF), de São Paulo, responsável pela primeira Marcha, realizada nesta capital, em 19 de abril de 1964. Cf., entre outros estudos, CORDEIRO, 2009.
}

Revista Caminhos da Educação: diálogos, culturas e diversidades. CAEDU/UFPI

Teresina, Brasil, v. 1, n. 2, p. 141-158, maio/agosto de 2019.

ISBN: 2675-1496 DOI: https://doi.org/10.26694/caedu.v1i2.9895 


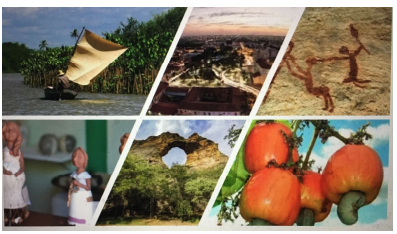

ISBN: 2675-1496 DOI: https://doi.org/10.26694/caedu.v1i2.9895

comprometidos com os mesmos, ${ }^{10}$ diferentes formas de mobilização se constituíram, no contexto da redemocratização, a partir dos anos 1980, inspiradas, em grande medida, por aquela tradição. Nesse novo cenário, marcado pela reorganização de movimentos sociais e pela retomada dos debates políticos, deu-se a formulação da Constituição de 1988 e da segunda Lei de Diretrizes e Bases da Educação Nacional, em 1996, quando importantes medidas foram alcançadas no campo educacional.

No momento presente, em que o retrocesso tem marcado aspectos diversos da vida política, social e cultural, também na educação brasileira conquistas democráticas parecem encontrar-se sob sério risco. Essa ameaça tem surpreendido aqueles que acompanham os debates educacionais brasileiros e consideravam que alguns pontos, obtidos desde os anos 1980, já se encontrariam assegurados, como a afirmação do papel central da escola pública na educação no país, do espaço escolar como lugar de diálogo, crítica e pluralidade, e dos direitos de educadores e educandos, entre os quais se situam o da liberdade de expressão, de ensino e de acesso ao conhecimento.

Contrapondo-se a perspectivas comprometidas com a construção da escola como um ambiente democrático, têm surgido propostas com vistas à intervenção nas práticas escolares que defendem a família como autoridade exclusiva na educação de crianças e jovens, esvaziando o papel da escola e de professores. Projetos com esse teor vêm sendo apresentados em inúmeras casas legislativas do país, em nível municipal, estadual e federal, integrando-se ao movimento "Escola sem Partido". ${ }^{11}$ Tais proposições apoiam a

\footnotetext{
${ }^{10}$ Entre os educadores que vinham, nos primeiros anos da década de 1960, conduzindo ações educativas comprometidas com a democracia, e que sofreram com a repressão conduzida após o golpe de 1964, podem ser citados Anísio Teixeira, então diretor do INEP e reitor da UnB, e Paulo Freire, coordenador do Programa Nacional de Alfabetização.

${ }^{11}$ As propostas desse movimento podem ser conhecidas por meio de consulta ao site "Escola sem partido"

(http://www.escolasempartido.org/). Análises críticas sobre o mesmo podem ser encontradas em espaços diversos de mobilização ocupados nas mídias digitais, congregando educadores, historiadores, e estudantes, como é o caso da página do Facebook intitulada "Professores contra o Escola sem partido". Muitas publicações recentes, inclusive oriundas dos meios acadêmicos, também têm tratado do tema, como, por exemplo, FRIGOTTO, 2017. Sobre sua situação no presente, ainda que tivesse havido um recuo no ano passado, com o arquivamento do projeto em tramitação no Congresso Nacional e queixas sobre dificuldades financeiras, em 2019, o EsP recobrou suas forças, e um novo projeto de lei foi apresentado no Congresso Nacional, reforçando pontos do anterior. Além da ação parlamentar, composta

Revista Caminhos da Educação: diálogos, culturas e diversidades. CAEDU/UFPI

Teresina, Brasil, v. 1, n. 2, p. 141-158, maio/agosto de 2019.

ISBN: 2675-1496 DOI: https://doi.org/10.26694/caedu.v1i2.9895 


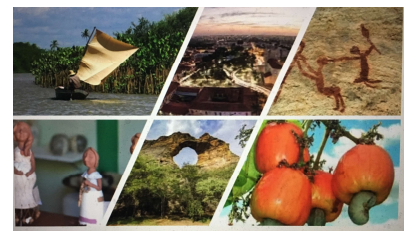

ISBN: 2675-1496 DOI: https://doi.org/10.26694/caedu.v1i2.9895

intromissão impositiva das famílias na escola, em nome de valores que dizem respeito ao espaço privado - com destaque para os religiosos -, em um viés coercitivo em relação a professores e professoras, a quem é negada a liberdade de ensinar. E ainda que os integrantes desse movimento mobilizem expressões como "liberdade e "democracia" em suas formulações - assim como o fizeram setores católicos em debates educacionais do passado - , as propostas defendidas possuem um claro viés autoritário, preconceituoso e mistificador, o que se observa, por exemplo, quando, criticando uma suposta hegemonia da esquerda nas escolas brasileiras, professores que estimulam a reflexão crítica em suas salas de aula são apresentados como "doutrinadores".

Composto e apoiado por setores conservadores, entre os quais se situam partidos políticos situados à direita e extrema-direita no espectro político - apesar do título dado ao movimento marcar um sentido crítico em relação à presença de viés partidário na educação -, grupos religiosos católicos, como no passado, a que se reuniram setores evangélicos, principalmente neopentecostais, ${ }^{12}$ esse movimento vem travando, nos últimos anos, uma acirrada disputa de espaço na cena educacional. Atuando em diversas frentes, como a parlamentar, tem se dedicado, ainda, à propaganda massiva dirigida à sociedade em termos mais amplos, e em especial, a famílias de alunos, buscando atrair o seu apoio. A grave ameaça representada por esse movimento para a afirmação de uma escola - em especial, no caso da escola pública - plural e aberta à vida, às diferenças e ao diálogo tem sido ressaltada por educadores, acadêmicos, entre outros, representando uma pauta muito importante na mobilização de setores progressistas da sociedade brasileira na atualidade.

ainda por diversos projetos tramitando em diferentes casas legislativas do país, ações de propaganda e de busca de apoio junto à sociedade também continuam intensas.

12 Torna-se importante atentar para o perigo da generalização quanto ao apoio de grupos religiosos cristãos ao movimento, que está longe de ser unânime. É necessário valorizar a dimensão plural que caracteriza esses grupos e a presença, em seu interior, de diversos segmentos e ações de oposição dirigidas a pautas conservadoras, como a do "Escola sem Partido". Um exemplo desse tipo de posicionamento pôde ser observado no evento intitulado "O Amor vence o Ódio - Caminhada e Vigília", no Rio de Janeiro, durante a campanha do segundo turno das Eleições de 2018. 


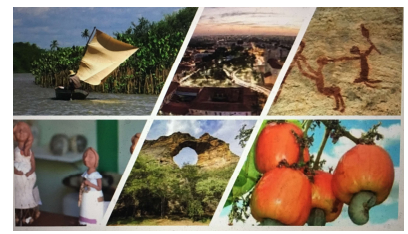

ISBN: 2675-1496 DOI: https://doi.org/10.26694/caedu.v1i2.9895

Como indica Marc Bloch acerca do ofício historiográfico, a forma como dirigimos nosso olhar ao passado tem como base a nossa experiência histórica e as questões que permeiam a nossa vida presente. ${ }^{13}$ No caso específico deste estudo, o diálogo com os debates do passado encontra-se ancorado em um panorama no qual esse outro debate vem mobilizando a sociedade brasileira e, em especial, o campo educacional, com aproximações em relação àqueles em curso em outros tempos. E refletir sobre o passado e sobre possíveis continuidades e descontinuidades entre esses tempos distintos tem-se mostrado como um caminho essencial para uma compreensão mais atenta dos dilemas do presente e para o enfrentamento dos graves desafios do nosso tempo, em que a defesa da educação democrática, mais uma vez, se apresenta como uma tarefa crucial. ${ }^{14}$

\section{REFERÊNCIAS BIBLIOGRÁFICAS:}

BLOCH, Marc. Apologia da História ou o oficio do historiador. Rio de Janeiro: Jorge Zahar, 2001.

CERTEAU, Michel, "Fazer com: usos e táticas" In Idem. A invenção do cotidiano: 1 Artes de fazer. Petrópolis, Vozes, 1994.

CHARTIER, Roger. A história cultural: entre práticas e representações. Lisboa: Difel; Rio de Janeiro: Bertrand Brasil, 1990.

CORDEIRO, Janaína M. Direitas em movimento: a Campanha da Mulher pela Democracia no Brasil. Rio de Janeiro: Ed. FGV, 2009.

FRIGOTTO, Gaudêncio (org.). Escola "sem" partido: esfinge que ameaça a educação e a sociedade brasileira. Rio de Janeiro: UERJ/LPP, 2017.

JUNQUEIRA, C. A luta contra a escola pública no Brasil. Boletim Servir. n.2. Ano XIII. ago.1960. Rio de Janeiro: AEC.

MONTALVÃO, Sergio. A LDB de 1961: apontamentos para uma história política da educação. Revista Mosaico. Rio de Janeiro: CPDOC/FGV, jul/2010. Disponível em: http://cpdoc.fgv.br/mosaico/?q=printpdf/artigo/ldb-de-1961-apontamentos-para-umahist $\% \mathrm{C} 3 \% \mathrm{~B} 3$ ria-pol\%C3\%ADtica-da-educa $\% \mathrm{C} 3 \% \mathrm{~A} 7 \% \mathrm{C} 3 \% \mathrm{~A} 3 \mathrm{o}$ (acesso em 08/10/2016).

13 BLOCH, 2001, P. 65. Também é bastante conhecida a frase de Lucien Febvre: "A história é filha do seu tempo".

${ }^{14}$ Sobre diferentes momentos do debate em que se afirmou a relação entre educação e democracia na sociedade brasileira, Cf. XAVIER, 2013, p.9-28. Sobre esse debate na atualidade, Cf. PENNA, QUEIROZ; FRIGOTTO, 2018.

Revista Caminhos da Educação: diálogos, culturas e diversidades. CAEDU/UFPI

Teresina, Brasil, v. 1, n. 2, p. 141-158, maio/agosto de 2019.

ISBN: 2675-1496 DOI: https://doi.org/10.26694/caedu.v1i2.9895 


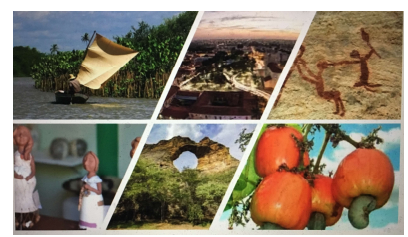

ISBN: 2675-1496 DOI: https://doi.org/10.26694/caedu.v1i2.9895

MOTTA, Rodrigo Patto Sá. "Em guarda contra o perigo vermelho”: o anticomunismo no Brasil (1917-1964). São Paulo: Perspectiva/FAPESP, 2002.

NÓVOA, Antonio. A imprensa de educação e ensino. In CATANI, Denice B. e BASTOS, Maria Helena C. Educação em revista: a imprensa periódica e a história da educação. São Paulo: Escrituras, 1997.

PENNA, F.; QUEIROZ, F.; FRIGOTTO, G. (org.) Educação democrática: antídoto ao Escola sem Partido. Rio de Janeiro: UERJ/LPP, 2018.

PIO XI. Carta Encíclica Divini Illius Magistri. Disponível em: http://www.vatican.va/content/pius-xi/pt/encyclicals/documents/hf pxi enc 31121929 divini-illius-magistri.pdf em (acesso em 17/12/2019).

SENRA, Alvaro de Oliveira. A "liberdade de ensino" e os fundamentos da ação política do segmento privado no Brasil entre 1945 e 1964. Revista Brasileira de História da Educação. v. 10, n.3. Campinas: Autores Associados, 2010.

SERVIR. Boletim da AEC do Brasil. Rio de Janeiro: AEC, 1952-1960.

XAVIER, Libânia. Manifestos, cartas, educação e democracia. In MAGALDI, Ana Maria e GONDRA, José G. (orgs). A reorganização do campo educacional: manifestações, manifestos e manifestantes. Rio de Janeiro: 7Letras, 2003.

Recebido: 02/04/2019

Aprovado: 25/06/2019 